\title{
Usage, attitudes and workload implications for a Web-based learning environment
}

\author{
Betty Collis* and John Messing** \\ *University of Twente, Netherlands \\ **Charles Sturt University, Australia \\ email:collis@edte.utwente.nl
}

At the University of Twente, a locally developed Web-based learning environment called the TeleTOP system is being implemented throughout the university after being first developed and used in the Faculty of Educational Science and Technology, followed by use in the Department of Telematics. Studying the usage choices of instructors with regard to tools offered by the system, as well as the instructors' workload implications and attitudes, is valuable not only for the implementation activities in the rest of the university, but more generally for those studying the impact on educational practice of Web-based learning environments containing course-management tools. This paper reports on a study of thirty-three TeleTOP-using instructors from the two faculties at the end of the 1999-2000 academic year. The results show that instructors feel that a major benefit of using the system is that it is a catalyst for a re-evaluation of one's own teaching; many instructors do not make use of the tailoring options; decisions about use of the system and the provision of feedback are based on the current instructional practices of the instructor; and instructors perceive increases in their workload to be a problem (when in fact the actual amounts of time spent vary considerably and include instructors with minimal investments).

\section{The TeleTOP system at the University of Twente}

The tools and features of Web-based course-management systems vary (see http://www.ctt.bc.callandonline/, for an analysis and comparison of several commercially available systems) but typically include tools to support the organization of the course, tools to support communication, tools to support student activities such as submission of assignments and collaborative work, and 'back-office' tools to handle user registration, maintenance of user data, and, in some systems, tools to tailor the view of a course site made available to a registered user (Robson, 1999). Although many tools and features are 
available in such Web-based learning environments, it is not the case that instructors necessarily make use of all these tools and features. Rankin (2000) for example, notes that 'most instructors have failed to take full advantage of the growing resources available to them online'. Rankin suggests that the creation and incorporation of templates into course Web sites could be a strategy to provide instructors with a simple and effective way of developing their Web-accessible materials. Such templates are the basic building blocks of the TeleTOP learning environment used at the University of Twente.

In the Faculty of Educational Science and Technology, there has been extensive pioneering experience with the use of Web-based tools and functionalities since early 1994 (for a review, see Collis and Moonen, 2001). In 1997, the faculty management decided to move from its pioneer experiences to a faculty-wide systematic use of a Web-based coursemanagement learning environment. The decision was not technology-driven, but strategic and educational. Firstly, it was strategic in that the faculty decided actively to pursue a new cohort: working students wishing to stay in their jobs and home communities. Secondly, it was educational in that these working students were not to be treated as a distinct 'distance education' cohort, but instead all students, regardless of location, were to benefit from a new version of the educational philosophy of the faculty, with the students as active contributors to their courses. Such aspirations had to be grounded in the reality base of the instructors: their available time, their willingness to use a Web-based system, their willingness to adapt to new cohorts of students and to a process of educational change. Because no existing system could be located that satisfied the core functional requirements derived to support this educational vision (Tielemans and Collis, 1999), the Tele TOP team produced its own system (for more information, see http://teletop.edte.utwente. $n l$ ).

A critical feature of the TeleTOP system is that instructors can determine themselves, before or during a course, which of more than thirty features or tools they wish to have in their course environments. These choices can be changed at any time, by the instructor, without need for technical-support staff intervention. The standard features from which instructors could choose in 1999-2000 were: news; roster (a complex, matrix structure via which assignments can be submitted, feedback given, course study materials made available, and course structure and time-tabling visualized); course information; email centre (allowing the instructor or students to form aliases for groups of students as well as send emails to any individual associated with the course); discussion forums; question and answer features; chat; various types of groupware tools; a glossary feature; templates for student presentations; a template for creating a page of Web links grouped into categories; multimedia archives; publication bibliographies; a quiz creation and management tool; administration tools for the instructor; search tools for both the Domino database itself and generally; and a variety of other options. In addition, instructors can request tools or features of particular value to their own courses. This list of choices is offered to the instructor as a clickable list via the TeleTOP Decision Support Tool, also part of the TeleTOP system (DeBoer and Collis, 1999).

\section{Comparison of use in a social science and technical faculty, 1998-1999}

The first version of the TeleTOP system was developed in the 1997-8 academic year and served as the basis for twenty-four 're-engineered' courses in the Faculty of Educational Science and Technology in the 1998-9 academic year. Also during the 1998-9 academic year, the Department of Telematics wanted to make use of TeleTOP for its courses, so 
preparations began for the use of the system in that department to start full-scale in the 1999-2000 academic year, with three pilot courses during 1998-9. During the 1998-9 academic year, evaluations were carried out of the TeleTOP experiences, in both the education and telematics faculties (Bloemen, 1999; De Boer and Collis, 1999; Fisser, Kamp, Van de and Slot, 1999). The most significant results of these evaluations indicated that instructors and students were satisfied with the TeleTOP system and believed it was contributing to positive changes in educational practice. There did not seem to be much difference between the instructors in the two faculties in terms of the functions they chose with the Decision Support Tool. However, points of concern in both the education and telematics faculties were that the instructors:

- were concerned about the higher time investments that would be needed on their parts;

- felt that they were spending large amounts of time in giving personalized feedback, while students did not always perceive the feedback as helpful or timely enough.

\section{Evaluation based on experiences in the 1999-2000 academic year}

In the 1999-2000 academic year, over eighty courses in the education faculty (all of the first- and second-year courses, all of the core courses in the Masters programme of the faculty, and a variety of the remaining courses) were re-engineered pedagogically and technically. In addition, all of the first-year courses in the telematics department (as well as courses in other faculties in our university and courses in a law faculty at another university, see Collis and De Boer, 2000) were converted. During the same period, the decision was made by the university management to extend the use of TeleTOP throughout the entire university so that students would have a consistent and powerful system to support their learning regardless of what faculty they attended. Thus the experiences of the two pioneering faculties became of particular importance in a practical sense as well as a conceptual perspective. Is TeleTOP suitable for use in other sorts of faculties different from the social-science setting in which it was created? How do technicalsubject instructors respond? In particular, an evaluation was conducted (Messing, 2000a) starting from the results of the 1998-9 experiences and including the following questions:

- What differences are detectable in the experiences of instructors in the two faculties (a social science and a technical faculty) in their use of TeleTOP, with regard to instructors' perceptions of learning impact?

- Why do instructors choose to use or not use certain TeleTOP features?

- What generalizations about workload changes, particularly with respect to the handling of feedback, can be made?

The remainder of this article discusses the main results of this evaluation.

\section{Method for the 1999-2000 evaluation}

The subjects consisted of instructors in the Faculty of Educational Science and Technology (called internally by the initials 'TO') and the Telematics department of the Faculty of Computer Science (called internally 'TE') who had redesigned and taught courses during the 1999-2000 academic year using the TeleTOP system. A total of thirtythree instructors, twelve from the Telematics department and the remainder from the 
Faculty of Educational Science and Technology responded. This represents a return rate of 75 per cent of the instructors using TeleTOP from the Telematics department and over 60 per cent of the instructors using TeleTOP from the Faculty of Educational Science and Technology. Of the respondents from the education faculty, eleven had also used TeleTOP in the 1998-9 academic year while for ten their use of TeleTOP in the 1999-2000 year was their first experience. Forty courses were represented in these responses (several instructors had more than one course in the sample).

A survey instrument consisting of checklist-type choices with opportunities for openended responses was prepared, piloted and revised. The questionnaire consisted of two parts, one a general summary of experiences and attitudes toward the use of the TeleTOP environment, and the second specific to each course that the instructor taught. Most of the data were collected by a combination of the survey and individual interviews with instructors during the last month of the 1999-2000 academic year.

\section{Results}

The following are some main aspects of the results (Messing, 2000a).

What is new in your teaching as a result of using TeleTOP?

The majority of the open-ended responses to these questions focused on improved opportunities for feedback provision. These were both qualitative, in terms of new ways of providing feedback (for example, peer evaluation), and also procedural (faster provision, via the course site, with feedback available on the course site, feedback to groups via the site). Other new teaching aspects included the reuse of student work as models, more personal feedback and improvements to presentation of material.

Have your students had a better learning experience than before?

The overwhelming majority of respondents were positive about the use of TeleTOP, even though they may have had some criticisms of one or more components. The primary reason for this positive attitude was a conviction of the value of a Web-based environment for learning. An interesting reference was made a number of times to the fact that the introduction of this new approach to teaching and learning provided a valuable opportunity for the instructor to re-think course goals, content and teaching strategies, which in turn impacted on the students.

With respect to TeleTOP providing a better learning experience than without it, nearly two-thirds of all the respondents indicated that the result was a better learning experience for students. The justifications were frequently not related to TeleTOP as such but had more to do with the process of systematically implementing a new teaching strategy involving the use of Web-based tools. A second general category of remarks was that TeleTOP provided increased flexibility for students as well as instructors. Providing a more flexible timeframe for the learning process rather than a rigid synchronization was seen as an important convenience factor for the student as well as the instructor. Having access to information and communication, assignments and feedback, regardless of location, was cited as an important benefit to both students and instructors.

Instructors also noted that their use of TeleTOP resulted in 'more activity and instruction of students' accompanied by 'an overview of the tempo of the learning and level of participation'. Students are 'stimulated to react/comment more intensely' with new options 
added to the learning process, for example, 'giving students the opportunity to exchange information - greater student interaction'. The course becomes 'more personal for students'. Finally, many instructors noted practical benefits (with educational implications) for students and themselves via the use of TeleTOP.

If there were no positive changes in the learning experience, why not?

However positive such observations were, the fact remained that approximately one-third of the respondents did not believe that their use of TeleTOP improved the learning experience in their courses (although none indicated that they felt the learning experience was worse). Examination of the justifications for this attitude revealed that many of these respondents admitted that they or their students were not using TeleTOP to its full potential or were simply using minimalist strategies to meet policy requirements. ('My material is basically a set of lectures, TeleTOP is not used to add anything extra'.) This is not an uncommon situation. Salomon (2000) calls it the 'domestification' of technology, to do nothing more than applying it to existing 'housekeeping'. Messing (2000b) analysed data from a comparable study, in which less than 10 per cent of a set of courses were able to meet even minimal criteria for conscientious use. Clearly there is a need to ensure that policies involving a Web-based learning environment are not just given token service.

\section{Use and perceived value of TeleTOP features}

The use and perceived value of TeleTOP features were measured by asking respondents to indicate which of the core set of TeleTOP features they had chosen for their courses, why they had or had not chosen the feature, and to give their rating of the different components according to usefulness. Figure 1 shows the percentage of feature selection for the two faculties.

A brief description of these features follows. The captions refer to, from left to right: news; roster; course information; email; discussion; question and answer; chat; 'BSCW' (the name of a shared workspace application); Workspace (a different groupware tool, also with shared workspace functionalities, but less complex than BSCW); presentation (where student work can be presented in a sort of showcase area); glossary; Web links; multimedia; publications; quiz (quiz-making tools); search; and free (to be designated as requested by the instructor). These are not the only functionalities available in TeleTOP, but rather the ones most commonly chosen by the instructors. There is no requirement imposed by the system or by either the Faculty of Educational Science and Technology or the Telematics Department as to what instructors must choose. The choice and combination is left to the instructor and can be altered at any time via a simple 'decisionsupport tool' in the system. The 'roster' is the most flexible and versatile of the functionalities. It is a tool by which an instructor can build a matrix to serve some sort of organizational role in the course (such as, one row per week or one row per topic; different rows for different groups, etc.). Also, each cell in the roster can be linked to different templates which in turn can be used for combinations of instructor-submitted resources and student-submitted assignments and resources.

As with the situation in the Faculty of Educational Science and Technology in the 1998-9 academic year (De Boer and Collis, 1999), the most highly rated features were the organizational ones (roster, news, and course information), a view shared in both faculties. By virtue of user choices, the organizational features have become a de facto core. The 


\section{Feature use by faculty}

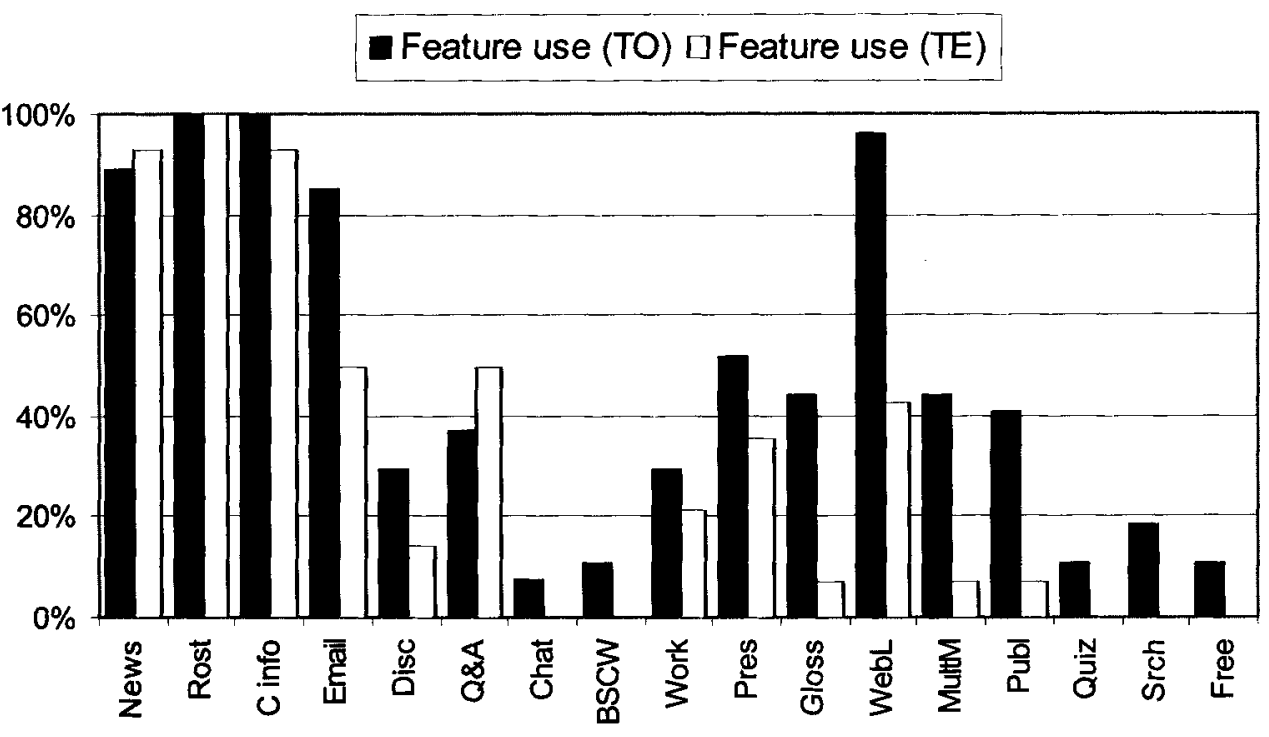

Figure 1: Use of TeleTOP features by faculty ('TO' are the Dutch initials for the Foculty of Educational Science and Technology, 'TE' for the Department of Telematics).

roster was becoming a key component for a resource-based learning (RBL) approach (Ling, 1997), indicating a shift from teacher-based lecturing to resource-based information organization.

In terms of differences between the faculties, it can be seen that the Education Faculty made considerably greater use of the email possibilities in the system, while the Telematics Department made greater use of the frequently asked questions area. In a comparison of choices within the Education Faculty itself between the 1998-9 and 1999-2000 academic years (De Boer and Collis, 1999) only three features showed any significant change. In the second cycle (1999-2000) there was a marked increase in the Faculty of Educational Science and Technology in the use of Web links ( 52 per cent up to 96 per cent) and frequently asked questions ( 5 per cent up to 37 per cent), and a decrease in the use of the glossary feature ( 71 per cent down to 44 per cent). The use of the roster, email, course information and news was full in both cycles. Analysis of the reasons for choosing or not choosing a particular feature revealed that the decisions about the use of a tool were based largely on the current practices of the instructors, but that a migration from support of existing practices to support of new practices can evolve over time and experience.

\section{Feedback and workload}

The increased activity of students leads to an increased need for feedback from the instructor. In the Faculty of Educational Science and Technology, for example, the average course included more than six rounds of student submissions, for assignments, discussions, 
partial versions of final projects, etc. For most instructors, this was much more interaction than they had been involved with before using TeleTOP. Instructors expressed many concerns about the time needed for feedback as well as the management of feedback. In another study, Van der Veen, De Boer and Collis (2000) analysed the types of feedback given by instructors in the Education Faculty in the 1999-2000 academic year and found the majority of instructors gave the most labour-intensive form of feedback: personal comments to each individual student (see Table 1). Many instructors took a pragmatic approach in limiting the time they spent giving feedback.

\begin{tabular}{|c|c|c|c|c|c|c|}
\hline Type of assignment & 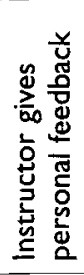 & 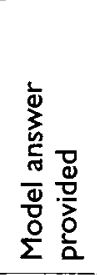 & 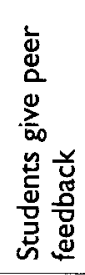 & 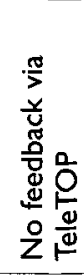 & 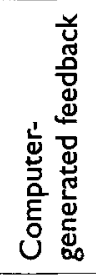 & ञٓ \\
\hline $\begin{array}{l}\text { I. Searching for new } \\
\text { information }\end{array}$ & 5 & & 1 & & & 6 \\
\hline 2. Case studies & 3 & 1 & & & & 4 \\
\hline 3. Role play & & | & & & & I \\
\hline 4. Reports & 1 & & & & & । \\
\hline $\begin{array}{l}\text { 5. Production of } \\
\text { multimedia } \\
\text { products }\end{array}$ & 2 & & 1 & 3 & & 6 \\
\hline $\begin{array}{l}\text { 6. Assignments } \\
\text { related to theory }\end{array}$ & 6 & & & 2 & & 8 \\
\hline 7. Skill practice & I & & & 3 & & 4 \\
\hline 8. Testing, quiz & & & & & I & 1 \\
\hline$\overline{\text { Total }}$ & 18 & 2 & 2 & 8 & $i$ & 31 \\
\hline
\end{tabular}

Table 1: Forms of feedback, Faculty of Educational Science and Technology 1999-2000, thirty-one courses.

In general, in both faculties, instructors in their first year of use simply tried to adapt their existing practices to TeleTOP or bypassed TeleTOP and persisted with their normal routine. More generally, instructors were asked to provide estimates of the amount of time they spent in organizing and delivering TeleTOP-based material. The estimates were collected for time spent prior to the start of the teaching period and time spent during the teaching period. There was a wide variability in the responses (of the twenty-nine giving estimates, the total time spent ranged between 6 and 488 hours with ten between 6 and 32 hours, thirteen between 38 and 80 hours, and eight between 102 and 488 hours (with six of these eight in the range 102-62 hours). Most instructors indicated that they just could not make a good estimate and were thus just guessing. For a 'new TeleTOP' course, instructors were likely to require a preparation time somewhere between 30 per cent and 150 per cent of the time allocated to the delivery of the course. Furthermore, the preparation time in 
subsequent sessions is likely to be reduced but not dramatically. However, the data revealed that those instructors most familiar with the system spent the most time. In subsequent interviews it became clear that these persons were also pioneers in the area, who regularly spent considerable time on preparation and delivery of their courses, trying new methodologies and technologies. For the majority of instructors, it cannot be said that their estimated time involvement for a semester-long course was excessive; however, baseline data from their ordinary situations were not available.

\section{Conclusions}

On the whole the strategy of progressive implementation of TeleTOP appears to have been positively received in both the Education Faculty and the Telematics department. In both, the existing practices and skills of an instructor play an important role in determining how a Web-based system will be adopted and used. Instructors are most likely to begin by choosing aspects of a system that reflect their current ways of teaching, and then gradually move to new instructional approaches and new features. A system should be flexible enough so that instructors can find a comfortable starting-point, but are stimulated rather than constrained by the system in moving beyond that starting-point. TeleTOP appears to offer these characteristics.

Workload is a significant consideration; most instructors felt that their workload had increased but found it difficult to quantify where or by how much. While the accuracy of instructor self-report with respect to workload is likely to be poor, it does seem that workload concerns are a relevant issue. Instructors spending the most time were pioneers putting in large amounts of time by choice, not because the new ways of teaching and of using the technology forced an increased workload upon them. Many instructors invested little time by either relative or absolute standards, and thus workload concerns may be for many instructors a matter of perception rather than of fact. The benefits of reduced faceto-face contact and greater flexibility in location (working from home or any part of the world) were recognized as real advantages, but the disadvantages of greater time involved in preparation and in more instances of contact with students, were also keenly felt. Managing to work 'smarter' with this technology rather than simply working harder is a goal that has not yet been achieved.

The answer to the general question underlying this study - "are technical-subjects instructors different from social-science instructors in their needs for a Web-based learning system?' - appears to be that the differences are not substantial. The experiences with TeleTOP in both faculties show that instructors will use new tools, if they perceive their educational relevance and management feasibility. However, there seem to be indications that the use of the tools beyond a minimum level will vary according to the individual unless sustained initiatives are in place to stimulate more creative teaching and learning approaches (Collis and Moonen, 2001). Getting instructors over the first obstacle of usage is a major step, and the faculties at the University of Twente are moving through this in rapid fashion. Getting instructors to delve more deeply into tailoring, and into finding workload-sustainable methods to handle different groups of students with different views of a course, is the challenge for the next period at the University of Twente. This problem will be even more difficult to confront than the initial implementation challenge. 


\section{References}

Bloemen, P. (1999), Evaluation TeleTOP and C@mpus+ 1998/99, End Report, Faculty of Educational Science and Technology, University of Twente, Enschede, NL.

Collis, B., and De Boer, W. (2000), 'The adaptation and use of a WWW-based coursemanagement system within two different types of faculties at the University of Twente', ED-MEDIA 2000 World Conference on Educational Multimedia, Hypermedia and Telecommunications, 28 June, Montreal, Canada.

Collis, B., and Moonen, J. (2001), Flexible Learning in a Digital World: Experiences and Expectations, London: Kogan Page.

De Boer, W. and Collis, B. (1999), 'How do instructors design a WWW-based course-support environment?', in B. Collis and R. Oliver (eds.), Proceedings of ED-MEDIA-99 World Conference on Educational Multimedia, Hypermedia and Telecommunications, Vol. 1., 299-304, Charlottesville, VA: AACE.

Fisser, P., Kamp, I. Van de, and Slot, C. (1999), 'TeleTOP at the Telematics Faculty', internal report, DINKEL Institute, University of Twente, Enschede, NL.

Ling, P. (1997), 'Evaluating teaching initiatives which employ resource based learning', available at http://www.ultibase.rmit.edu.au/Articles/lingp2.htm.

Messing, J. (2000a), 'A report of the TeleTOP survey', May 2000, internal report, DINKEL Institute, University of Twente.

Messing, J. (2000b), 'A study of the use of on-line supported learning facilities at Charles Sturt University', ED-MEDIA 2000 World Conference on Educational Multimedia, Hypermedia and Telecommunications, 28 June, Montreal, Canada.

Rankin, W. (2000), 'A survey of course Web sites and online syllabi', Educational Technology, $40(2), 38-42$.

Robson, R. (1999), 'Course support systems: the first generation', International Journal of Educational Telecommunications, 5 (4), 131-42.

Salomon, G. (2000), 'It's not just the tool, but the educational rationale that counts', $E D$ MEDIA 2000 World Conference on Educational Multimedia, Hypermedia and Telecommunications, 28 June, Montreal, Canada.

Tielemans, G., and Collis, B. (1999), 'Strategic requirements for a system to generate and support WWW-based environments for a faculty', in B. Collis and R. Oliver (eds.), Proceedings of ED-MEDIA 1999: World Conference on Educational Multimedia, Hypermedia and Telecommunications, Vol. 1, 346-51, Charlottesville, VA: AACE.

Van der Veen, J., De Boer, W., and Collis, B. (2000), 'Didactics for Web learning environments: active learning', Technical Report, TeleTOP Alpha-Beta Project, DINKEL Institute, University of Twente. 